\title{
nature
}

Vol 441 | Issue no. 7089 | 4 May 2006

\section{Painful transition at the NIH}

\section{Elias Zerhouni has a mixed track record as director of the world's largest research agency - but the thrust of his reform effort should be supported.}

eading the National Institutes of Health $(\mathrm{NIH})$ under the presidency of George W. Bush was always going to be a challenging assignment. That much was clear four years ago this week, when Elias Zerhouni, an Algerian-born radiologist with a strong administrative track record at Johns Hopkins University, was confirmed in the position by the US Senate.

Zerhouni has, on the whole, handled this potentially poisoned chalice adroitly (see page 17). But this year, as three years of flat budgets begin to bite, Zerhouni's tenure at the NIH is being openly attacked by some scientists. The focus of their ire is his 'Roadmap', a set of activities that run across different NIH institutes and attempt to implement Zerhouni's vision for the agency. The critics say that the Roadmap isn't working and is diverting resources and attention from basic scientific research.

There are three obvious responses to this criticism. The first is that the Roadmap expresses priorities for the NIH - including the more effective translation of basic research results into clinical practice that most biomedical researchers would support and that any NIH director would need to implement at this time. The second is that it is not Zerhouni's fault that he is presiding over a period of flat budgets at the NIH, after the historic doubling of the agency's budget from 1998 to 2003.The third is that, in light of that doubling, public attacks on the Roadmap by what is now a rather well-funded community of biologists are going to make that community look bad.

Since its publication in 2003, the Roadmap has been the defining tenet of Zerhouni's directorship. By pushing for more interdisciplinary research, closer cooperation between the NIH's 27 historically independent research institutes and the rapid application of research results in the clinic, it addresses clear deficiencies in the NIH's previous performance. It also takes the agency in a direction that was called for by the Institute of Medicine in a landmark 2003 report, 'Enhancing the vitality of the National Institutes of Health'.

Funding for Roadmap activities is relatively modest - about $\$ 400$ million annually in a $\$ 28$-billion agency. But its influence is more pervasive than that number would suggest, and that is as it should be. Basic molecular biology will remain a critical component of NIH work but it will take place within a broader mandate of applying research to the good of public health. That is essentially what Zerhouni is trying to achieve, and his efforts deserve support.

\section{Bush's man}

Some of Zerhounis problems with NIH scientists originate not in his Roadmap goals, but rather with his being an appointee of President Bush. He arrived when the NIH, despite its budgetary expansion, was chafing under a number of centralization efforts led by the then health secretary, Tommy Thomson, which were rightly perceived as threatening the agency's autonomy and credibility.

Although Thomson has gone, the NIH director has not been able to wrest back the independence (to put out their own press releases, for example, or send who they like to scientific meetings) to which the NIH institutes are accustomed. NIH scientists might support Zerhouni more enthusiastically if they believed he had defended the agency's traditional autonomy as vigorously as possible.

Another important challenge for Zerhouni has been to explain in straightforward terms to Congress what the NIH has done with its increased budget. With the exception of the Roadmap, there's not much evidence that the strategic opportunity presented by the budget's doubling has been fully grasped.

The doubling took place during a leadership transition from Harold Varmus, through the prolonged interim directorship of Ruth Kirschstein, to the period when Zerhouni was finding his feet. As a result, there was no clear and consistent strategy for using the money. Individual institutes got
"NIH scientistsmight support Zerhounimore enthusiastically if they believed he had defended the agency's autonomy as vigorously as possible." their piece and moved on. A particular concern was that not enough young scientists were winning first-time grants during the most creative period of their careers. Zerhouni can't tell the institutes who to give grants to but he could, for example, have published data that would have exposed the failure of some institutes in this regard.

\section{Surviving scandal}

The other big event of Zerhouni's tenure has been a conflict-ofinterest scandal that racked the NIH's main campus at Bethesda, Maryland, during 2004 and led to the introduction of stringent new rules governing its scientists' interaction with business. These rules are unpopular, but Zerhouni had to come down hard after congressional investigators unearthed a trove of commercial interactions of which the NIH itself had no record. That being said, a leader who inspired more loyalty and devotion from his troops might have won more understanding of what had to be done.

Partly as a result, the Bethesda campus - now probably the largest single research facility in the world - is not a particularly happy place. Post-2001 security measures have further battered its collegial ambiance, and back-biting is seldom far beneath the surface.

Improving coordination between the institutes remains a difficult issue for any NIH director. On his departure, Harold Varmus floated ideas for radical reorganization (see Nature 418, 572; 2002) but, given the powerful backers for each institute's autonomy and the sheer inertia of US federal government, nothing has come of these.

The Roadmap makes the director's office more powerful than before, and that was a necessary change. On balance Zerhouni is doing a demanding job reasonably well. But he needs to work harder at persuading his staff and grantees that he is on their side. 